\title{
Longitudinal Study of EFL Students Using the Systemic Functional Linguistics Method
}

\author{
Akiko Nagao $^{1}$ \\ ${ }^{1}$ Faculty of International Studies, Ryukoku University, Kyoto, Japan \\ Correspondence: Akiko Nagao, 67 Tsukamoto-cho, Fukakusa Fushimi-ku, Ryukoku University Kyoto 612-8577, \\ Japan. Tel: 81-075-642-1111. E-mail: nagao@world.ryukoku.ac.jp
}

Received: May 25, 2017

Accepted: July 9, 2017 Online Published: October 28, 2017

doi:10.5539/ies.v10n11p47

URL: https://doi.org/10.5539/ies.v10n11p47

\begin{abstract}
This study examined the progress of English as a foreign language (EFL) writers using the instructional framework of systemic functional linguistics (SFL) and the communities of practice (CoPs) model. The study participants comprised 11 first-year undergraduate students in Japan with intermediate-level English proficiency who were exposed to SFL in a single EFL classroom (CoP). The participants' genre understanding and meaning-making decisions when writing discussion essays were studied over two semester-long courses. To do so, their developmental changes were analyzed using pre- and post-instructional writing tasks. In particular, their ability to convey interpersonal meaning, such as through the use of modal verbs, was examined and compared between the pre- and post-tasks. To triangulate the findings, participants' genre awareness in relation to discussion essays was also examined using in-depth qualitative analysis of their self-reflective texts and peer assessments, based on a grounded theory approach. In the pre-writing task, it was apparent that the learners lacked understanding of the components of discussion essay writing. However, analysis of their post-instructional tasks revealed that most had begun to apply the language components required to convey interpersonal meaning in their discussion genre texts. These results suggest that the changes in learner's genre awareness and knowledge affected the lexicogrammatical features they used when writing discussion essays. Thus, this study concludes that applying the SFL framework to writing instruction enhanced EFL learners' awareness of textual meaning and their understanding of the function of discussion essay texts.
\end{abstract}

Keywords: community of practice, EFL writing proficiency, longitudinal study, genre-based approach, grounded theory

\section{Introduction}

By exposing Japanese learners to the instructional framework of systemic functional linguistics (SFL) and the theoretical framework of communities of practice $(\mathrm{CoPs})$, this study investigated the writing proficiency and genre awareness of English as foreign language (EFL) writers. Previous studies on student writing, such as those by Mohammad and Hazarika (2016) and Al Badi (2015), have noted that learners understanding of language use in academic writing tasks is inadequate. Aguirre-Muñoz, Park, Amabisca, and Boscardin (2009) found that learners tend to "produce mere recounts of temporal events, lacking analysis of the events in terms of how they reveal character traits. This is evidenced by the overuse of action verbs (and underuse of mental verbs) and lack of modality" (p. 300). In other words, although learners need to improve the accuracy of their rhetorical and lexicogrammatical choices to correctly convey their intended message in writing tasks (Horowitz \& Samuels, 1987), most learners lack the requisite understanding to do so. Furthermore, while Sasaki and Hirose (1996) emphasized the need for L2 writing metaknowledge, writing instruction in Japanese EFL classrooms is largely limited to sentence-level grammatical features and translation, with little or no focus on metaknowledge (JACET, 1995). Yang and Goodyear (2004) argued that by using a genre-based instructional framework, learners may develop both metaknowledge of text types as well as an awareness of the social context and purpose of different text types. The SFL and genre-based approach to language learning enable learners to connect the lexicogrammatical features of texts with their purposes (Nishijo, 2017) and the benefits of applying the SFL approach to academic language lie in the teaching methodology, which includes deconstructing linguistic structures, a feature that makes the linguistic expectations of academic language explicit to learners and teachers (O’Donnell, 2011). 
Additionally, applying the CoP concept to an EFL classroom context allows us to understand "how participants connect, sharing individual information and stories, and [how] the participants gain knowledge and share it" (Cambridge, Kaplan, \& Suter, 2005, p. 1). Lave and Wenger (1991) illustrated how learners in CoPs engage in legitimate peripheral participation, which refers to the way in which newcomers become part of a CoP by interacting with other members. This process allows us to understand participants' learning: Through their repeated social interactions with other members, participants come to understand the meaning-making processes of the CoP and take on appropriate roles (Funatsu \& Hougetsu, 1995). That is, through interaction and observation, members gradually gain experience and eventually become core and active members (Wenger, McDermott, \& Snyder, 2002), in a process that is applicable to many types of communities and organizations and that plays an important role in establishing successful institutions ( $\mathrm{Li}$, Grimshaw, Nielsen, Judd, Coyte, \& Graham, 2009; Preece, 2004). Utilizing the SFL approach to genre writing and the concept of CoPs has been explained as follows: "genre writing evolved in a culture to achieve common social purposes that are recognized by members of the culture and communities" (Martin \& Rose, 2012, p. 58). The stages of SFL and genre in which learners engage in the classroom are generally predictable for members of the culture and its communities (Martin \& Rose, 2012).

In this study, the genre-based approach to language learning based on SFL was used. Genre not only comprises a staged activity, but is also goal-oriented and purposeful (Martin, 1984). It reflects the fact that people use different language in different contexts, and that language use and rhetorical meaning can vary accordingly (McCarthy, 1998). To become effective writers, learners must thus learn how to select and apply the appropriate lexicogrammar, which is the goal of the genre-based learning approach. However, reflecting the fact that this approach is rarely adopted in Japanese EFL contexts, this study was conducted to answer the following research questions: (1) How do Japanese EFL learners approach genre-type writing tasks and what lexicogrammatical features do they use to produce written texts?; and (2) How do Japanese EFL learners' meaning-making decisions and genre awareness improve as they engage in peer assessment of writing tasks?

\section{Literature Review}

\subsection{Communities of Practice}

Sugihara (2006) defined a $\mathrm{CoP}$ as a group of people with diverse interests and ideas who possess a shared understanding of the meaning, goal, and function of their activities and engage in practice together. As explained by Lave and Wenger (1991), a CoP enables its members to acquire skills and knowledge by participating in practical activities with other community members. They described learning as something situationally embedded, rather than a planned, mechanistic process of cognitive transmission. Reproducing other people's pre-existing knowledge is not "learning"; rather, learning clarifies other people's actions and thoughts within the context of participation in an activity, for example, the way in which people respond to issues within the group, achieve objectives, and solve problems (Lave \& Wenger, 1991).

Wenger (1998) defined a CoP as a group whose members mutually engage in an activity. His research was the first to discuss the relationship between members' identities and the CoP. As pointed out by Cox (2005), the original definition of $\mathrm{CoP}$ did not discuss in detail the potential risk of conflict and harm that accompanies the interactions between incoming members and existing members of the community.

Finally, Wenger et al.'s (2002) research expanded on the work of Wenger (1998), in presenting a conceptual definition of CoPs that encompassed all previous research. In this study, a $\mathrm{CoP}$ was defined as "a group of people with something in common, namely, a problem or set of problems, a passion about a topic, or a desire to deepen their knowledge and skills within the context of the community" (Wenger et al., 2002, p. 4).

\subsubsection{Degrees of Participation}

Wenger et al. (2000) argued that members play different roles within the CoP according to their respective degrees of participation, which can be categorized as core, active, or peripheral. Through regular social interaction, group members begin to gauge what involvement in the group looks like and what the learning process will comprise (Funatsu \& Hougetsu, 1995). Members then assume the roles that seem most suitable for them (Funatsu \& Hougetsu, 1995).

Core members act as leaders and coordinators and tend to do most of the speaking in debates and meetings (Wenger et al., 2002). As newcomers expand their knowledge and capabilities, they may advance to a deeper level of participation and eventually become core members (Tanaka, 2008).

Active members regularly attend meetings and debates, but unlike core members, they tend to be more reserved and may lack assertiveness when they do speak (Wenger et al., 2002). As defined by Wenger et al. (2002), 
regular participation is the basic criterion for active membership. Finally, most members in any community of practice are peripheral members, whose participation is only marginal and who tend to spend much of their time observing the core and active participants (Wenger et al., 2002).

Yet, despite the wide acceptance of these categories of membership, it is questionable whether the above definitions can be applied in a language-learning environment (Agterberg, van den Hooff, \& Huysman, 2011). Most existing definitions of core and active membership are vague, which is why, in this paper, I propose the need for more precise definitions of the degrees of participation that can be applied in the context of higher-education language learning.

\subsection{Systemic Functional Linguistics}

SFL has two main aspects: (1) how people use language rather than what people use language for, and (2) how language is structured for use (Eggins, 2004). The SFL framework views language as "a strategic, meaning-making resource" (Eggins, 2004, p. 2) and "explores how language is used in social contexts to achieve particular goals" (O'Donnell, 2011, p. 2). According to SFL, language and social contexts are strongly related to the use and function of language (Halliday \& Matthiessen, 2004). In other words, the SFL approach allows language users to focus on meaningful and appropriate choices (Halliday \& Matthiessen, 2004): With ideational, interpersonal, and textual meanings in mind, people consciously and subconsciously choose grammatical patterns and words in linguistic units to conventionalize coding systems and organize them as sets of choices (Eggins, 2004). Moreover, SFL identifies the three features of mode, field, and tenor as having convincing and predictable impacts on language use. In the SFL context, mode refers to the semiotic distances between, for example, written and spoken texts field refers to the descriptions of the participants, processes, and circumstances in which the activities occur; and tenor refers to relationships between the people who involved in (Martin, 2001). In SFL, the function of language is to convey ideas, and texts serve a distinct social function to convey information and establish social relations (O'Donnell, 2011).

\subsection{Genre and the Genre-Based Approach to Writing}

Genre is a social process and social activity that has sequential stages with certain purposes and goals in social activities (Wu \& Dong, 2009). The social activities of genres differ from their situational and cultural contexts (Wu \& Dong, 2009). In this article, genre pedagogy refers to Vygotskian learning theory, in which learners gradually gain independence in producing genre texts by participating in the school and community (Derewianka, 2003). The concept of genre is similar to that of CoPs, in that learning is a social process involving interactions with more socially capable others, and learners can progress from the zone of proximal development (ZPD) to that of actual development (ZAD) (Vygotsky, 1987). The ZPD concept is embedded in the genre approach to language learning through the learning cycle (Feez, 1998; Rothery, 1996; Martin \& Rose, 2008) and the stages of Feez's (1998) learning and teaching cycle are as follows: (1) building the context, (2) modeling and deconstructing the text, (3) joint construction of the text, (4) independent construction of the text, and (5) linking related texts. These stages allow learners to gradually understand the target genres' structure and language features, eventually enabling them to write the target genre text independently. In other words, they gradually progress from novice to experienced learners by participating in the learning community, an idea that is similar to Lave and Wenger's (1991) concept of the CoP.

\section{Method}

\subsection{Research Questions}

This study examined the performance of undergraduate EFL learners on SFL genre-based reading and writing tasks during a one-year course (two semesters), and was guided by the following research questions:

(1) How do Japanese EFL learners' lexicogrammatical choices when writing discussion essays change over two semesters?

(2) How do Japanese EFL learners' genre knowledge and awareness change over two semesters?

\subsection{Participants}

Eleven first-year students were selected from an EFL classroom at a large private university in Japan to participate in this study, which took place over two semesters of the 2016 academic year. All participants were international studies majors specializing in areas such as communication, languages, ethics, or globalization, who were taking semi-structured English for Academic Purposes (EAP) classes in their first year. Most were at an intermediate proficiency level, with scores averaging approximately 511 on the TOEFL PBT (CEFR A2 - B1). Written informed consent was obtained from all study participants to publish this study and all accompanying 
images. To assess their previous L2 writing experience in high school, participants completed a survey at the beginning of the first semester of 2016. The survey questions were based on Browne and Wada's (1998) work, and the results revealed that, regardless of their proficiency levels, the learners' previous writing experience was limited. Thus, they were considered to be novices in the genre approach to language learning. The results of the survey are shown in Table 1.

Table 1. Learners' background information

\begin{tabular}{llc}
\hline & Writing activities in high school & $\%$ \\
\hline 1 & Translation and grammar practice & 31 \\
2 & Paragraph writing & 15 \\
3 & Peer essay analysis & 5 \\
4 & Genre-based language learning & 3 \\
\hline
\end{tabular}

Note. These percentages pertain to the percentage of students who engaged in these activities.

\subsection{Instructional Procedure and Context}

The instructional context of this study comprised two 15-week semesters of genre-based EFL writing and reading courses offered by the faculty of international studies in a Japanese university. The author taught the lessons, which were based on the work of Halliday (1994), Martin (2009), Knapp and Watkins (2010), Rose (2011), Chen and Su (2012), and Troyan (2013), and familiarized learners with genre texts of varying degrees of complexity, from recount to discussion (Martin \& Rose, 2012). Feez's (1998) learning and teaching cycle-(1) building the context, (2) modeling and deconstructing the text, and (3) independently constructing the text-was applied three times in each semester. In Stages (1) and (2), participants learned about the meaning, structure, and language features of the target genre (20 minutes). In Stage (3), learners conducted timed writing tasks (50-60 minutes) to produce a target genre text, in this case discussion essays. They then engaged in peer assessment of the essays with a focus on finding the interpersonal meanings conveyed, such as modal verbs and adverbs; textual meanings such as contrastive conjunctions; and experiential meanings (Knapp \& Watkins, 2010; Yang, 2010; Halliday \& Matthiessen, 2014). Sample guiding questions for the peer assessment task are presented in Table 2. Learners were prompted to analyze how modal verbs were expressed by the writer and how the information and lexicogrammatical resources helped transition the writing from one paragraph to the next. This helped to increase learners' genre awareness by encouraging them to reflect on their writing (Yasuda, 2011).

Table 2. Questions for the peer assessment task

\begin{tabular}{l}
\hline 1. Content \\
\hline Which sentence serves as the topic sentence? \\
How is supporting evidence used in each paragraph? \\
\hline 2. Language features \\
\hline What kinds of lexicogrammatical features are used to express the writer's opinion? \\
What kinds of lexicogrammatical features are used to introduce different opinions?
\end{tabular}

\subsection{The Target Genre of this Study}

In this study, the target genre was the discussion text. Discussion texts introduce an issue and explore different ideas before ending with a personal opinion or comment. They are structured into four paragraphs. In the introduction paragraph, the topic is introduced and some background information given. In the second and third paragraphs, the pros and cons of the topic are provided. The final paragraph contains the author's opinion on the topic. Each paragraph should include a topic sentence and supporting evidence. The discussion essay uses such language features as modalities such need to and should to construct personal meaning and conjunctions such as however for textual meaning (Knapp \& Watkins, 2010). English modal verbs include can, could, may, might, shall, should, will, would, and must, which contain interpersonal meanings and functions or refer to the degree of possibility or frequency of an action (Mao, Li, \& Xue, 2014). According to Zhuanglin (2005) and Guanxia (2006), understanding of modality can be divided into high, medium, and low levels. Furthermore, modal verbs are usually used to determine different values of possibility and/or frequency, obligation, and inclination (Mao et al., 2014). Thus, it is essential for learners to understand the uses of modal verbs in writing discussion essays.

\subsection{Data Sources}

\subsubsection{Pre- and Post-Instructional Writing Tasks}

The learners were then given 60 minutes to write a discussion essay using the following prompts: (1) Do you 
agree or disagree with the practice of euthanasia? (2) Do you agree or disagree with the death penalty?

\subsubsection{Interviews}

Semi-structured interviews were conducted with five learners, in their L1 (Japanese), to collect qualitative data on their progress at the beginning, middle, and end of the semester. The interview data at the end of the second semester was then used for this analysis which allowed the participants to discuss the depth of their genre awareness of their pre- and post-discussion essays during the interview. Three learners who made similar lexicogrammatical choices in their discussion essays were chosen for the data analysis. The interview questions concerned (1) changes in their language proficiency, (2) changes in their relationships with their peers, and (3) changes in their identities as novice learners. The data from question (1), especially regarding their awareness of genre writing, were then analyzed. Each interview took approximately 60 to 90 minutes.

\subsubsection{Self-Reflection Written Texts}

To attain in-depth qualitative insights into changes in the learners' genre awareness and perceptions, self-reflection written texts were collected. For the pre-task, at the end of the semester, when the learners completed their peer assessments and shared the results with their group members, they were asked to reflect on their task participation using the following open-ended question: What are the most important things to know when completing a peer assessment of a discussion genre text? (Yasuda, 2015). The reflection tasks were conducted in Japanese during the 90-minute class period and took approximately 30 to 40 minutes to complete.

\subsubsection{Survey}

To assess changes in the learners' degrees of participation, pre-, mid-, and post-instructional surveys were conducted. On each occasion, the learners were asked to reflect on their classroom participation, membership, and the following open-ended question: In your opinion, are you a core, active, or peripheral member of this class during writing/reading/listening/speaking tasks? Explain your answer. At the beginning the each semester, the teacher explained the original concept from Lave and Wenger's (1991) core, active, or peripheral members.

\subsection{Data Coding and Analysis}

Three data sources-discussion essays, self-reflection written texts, and surveys-were collected at the end of each semester, while the interview data were collected only at the end of the second semester. The data collection dates are summarized in Table 3.

Table 3. Data collection dates

\begin{tabular}{lcc}
\hline & First semester, 2016 & Second semester, 2016 \\
\hline Discussion essay (argumentative essay) & $2016 / 07 / 07$ & $2016 / 12 / 15$ \\
Interviews & -- & $2017 / 1 / 18$ \\
Self-reflection written texts & $2016 / 07 / 11$ & $2016 / 12 / 19$ \\
Surveys & $2016 / 07 / 11$ & $2016 / 12 / 19$ \\
\hline
\end{tabular}

To analyze the language chosen by learners to convey personal meaning, all sentences produced by the learners were examined with respect to the lexicogrammatical decisions they had made therein. The modal verbs used were also analyzed to determine how the writer had argued his/her position (Knapp \& Watkins, 2010). To understand learners' genre awareness, their self-reflection written texts were analyzed using the grounded theory approach, which provides a qualitative research perspective by creating theories based on qualitative data (Flick, 2014; Saiki-Craighill, 2014; Terashita, 2011). The Grounded Theory Approach (GTA) focuses on visualizing how people who have experienced events that happen during mutual interactions develop an understanding of the meaning of these events (Saiki-Craighill, 2014). The goal of this approach is not to simply summarize the phenomenon, but rather to make inferences about the origins of opinions and behaviors that the subject of the investigation may not be aware of themselves. This is achieved by conceptualizing data, and investigating possible causes for these opinions and behaviors (Saiki-Craighill, 2006). Furthermore, the method considers conceptualized patterns, from which it derives universalities (Saiki-Craighill, 2006). The data analysis steps followed in the GTA are: (1) obtaining the data, (2) coding, (3) segmentation of data, (4) open coding, (6) selective coding, (6) continuous comparative analysis, and (7) theoretical saturation (Kinoshita, 2003). Unique theoretical concepts are constructed in an integrated manner and converted into explanatory diagrams, which constitute the most important output from the analysis (Saiki-Craighill, 2014). 


\section{Results}

\subsection{Research Question 1}

This study investigated how learners' knowledge and awareness of discussion essays changed over the course of two semesters and how this was reflected in their choices of lexicogrammatical elements to add interpersonal meaning to their texts. The word counts of learners' discussion texts in the first and second semester are summarized in Table 4, showing that the average word count was similar between the two semesters.

Table 4. Word counts of learners' discussion essays in the first and second semesters

\begin{tabular}{|c|c|c|c|c|}
\hline First semester 2016 & Length: & Text complexity: & Ay word lenoth in each sentence & Ayerage sentence lenoth in words \\
\hline Student no. & Words in text: & Sentences in text: & Av. word lengun in eacn sentence & 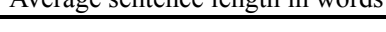 \\
\hline 1 & 212 & 17 & 4.73 & 12.4 \\
\hline 2 & 230 & 17 & 4.88 & 13.5 \\
\hline 3 & 184 & 10 & 4.62 & 18.4 \\
\hline 4 & 273 & 23 & 4.51 & 11.8 \\
\hline 5 & 167 & 11 & 4.58 & 15.1 \\
\hline 6 & 240 & 10 & 4.75 & 24 \\
\hline 7 & 266 & 21 & 4.85 & 12.6 \\
\hline 8 & 203 & 10 & 4.35 & 20.3 \\
\hline 9 & 258 & 21 & 4.87 & 12.2 \\
\hline 10 & 326 & 22 & 4.29 & 14.8 \\
\hline \multirow[t]{2}{*}{11} & 219 & 15 & 4.65 & 14.6 \\
\hline & 2578 & 177 & 51.08 & 169.7 \\
\hline$\underline{M}$ & 234.4 & 16.1 & 4.6 & 15.4 \\
\hline $\begin{array}{l}\text { Second semester } 2016 \\
\text { Student no. }\end{array}$ & Words in text: & Sentences in text: & Av. word length in each sentence & Average sentence length in words \\
\hline 1 & 159 & 12 & 4.78 & 13.2 \\
\hline 2 & 157 & 10 & 5.09 & 15.7 \\
\hline 3 & 302 & 15 & 5.14 & 20.1 \\
\hline 4 & 229 & 12 & 4.67 & 19 \\
\hline 5 & 244 & 16 & 5.06 & 15.2 \\
\hline 6 & 229 & 19 & 4.68 & 12 \\
\hline 7 & 206 & 15 & 4.83 & 13.7 \\
\hline 8 & 244 & 15 & 4.51 & 16.2 \\
\hline 9 & 251 & 14 & 4.52 & 17.9 \\
\hline 10 & 216 & 15 & 5.11 & 14.4 \\
\hline \multirow[t]{2}{*}{11} & - & - & - & - \\
\hline & 2237 & 143 & 48.39 & 157.4 \\
\hline M & 223.7 & 14.3 & 4.839 & 15.74 \\
\hline
\end{tabular}

Note. Student 11 did not permit his/her data to be used for the analysis.

The number of modal verbs used in discussion essays in the first and second semesters are summarized in Table 5. The numbers reported represent the mean number of learners who included each of the modal verbs listed, amongst the total number of essays.

Table 5. The mean number of modal verbs in all learners' essays

\begin{tabular}{lccccccc}
\hline & & Will & Could & Should & May & Can & Must \\
\hline 1st semester & Total & $14(25 \%)$ & $2(4 \%)$ & $19(39 \%)$ & $2(4 \%)$ & $18(33 \%)$ & $0(0 \%)$ \\
\cline { 2 - 8 } (Pre-writing) & $\mathrm{M}$ & 1.4 & 0.2 & 1.9 & 0.2 & 1.8 & 0 \\
\hline 2nd semester & Total & $15(32 \%)$ & $3(6 \%)$ & $21(45 \%)$ & $0(0 \%)$ & $6(13 \%)$ & $2(4 \%)$ \\
\cline { 2 - 8 } (Post-writing) & $\mathrm{M}$ & 1.5 & 0.3 & 2.1 & 0 & 0.6 & 0.2 \\
\hline
\end{tabular}

Note. "Total"; the total number of the frequency in 10 essays.

A sample discussion essay is shown in Figure 1. The results imply that although the learners had less previous experience of discussion essay writing and minimal formal instruction in English paragraph writing, their 
frequency of use of the words will, should, and can was high in the pre-writing task. However, this does not indicate that the learners understood the distinction between these modal verbs or in which paragraphs they should be used. The results also indicate that although the language features of discussion essays were explained to learners in the same way during the modeling text stage in both semesters, their frequency of use of the words will and should increase in the second semester.

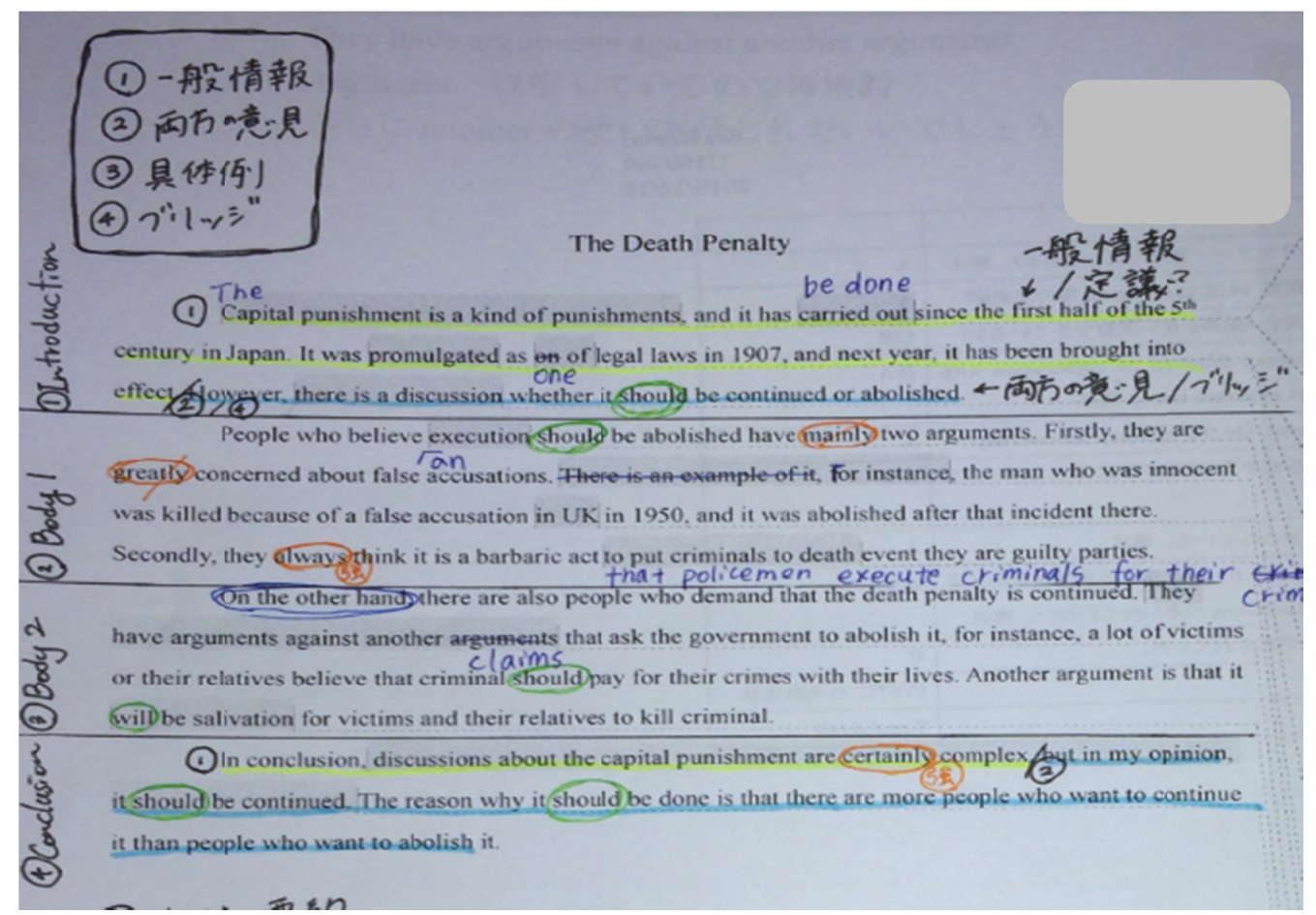

Figure 1. Student No. 3's Discussion Essay

The frequency of use of the modal verb should in each paragraph of the discussion essays in the first and second semesters are summarized in Table 6 . In both the pre- and post-instruction writing tasks, the learners tended to write should in the final paragraph, although some learners chose to use it in every paragraph. To understand their meaning-making decisions during the writing task, the interview data were analyzed and will be discussed in the next section.

Table 6. Frequency of use of the modal verb should in each paragraph of the discussion essays in the first and second semesters

\begin{tabular}{|c|c|c|c|c|c|c|c|}
\hline Student No. & 2nd paragraph & 3rd paragraph & $\begin{array}{c}\text { Conclusion } \\
\text { (includes writer's opinion) }\end{array}$ & Introduction & 2nd paragraph & 3rd paragraph & 4th paragraph \\
\hline 1 & For & Against & For & 0 & 0 & 0 & 0 \\
\hline 2 & For & Against & For & 1 & 0 & 0 & 0 \\
\hline 3 & For & Against & Both & 0 & 0 & 0 & 1 \\
\hline 4 & Write the definition & For & For & 1 & 0 & 0 & 1 \\
\hline 5 & For & Against & For & 0 & 0 & 0 & 0 \\
\hline 6 & For & Against & For & 0 & 0 & 1 & 2 \\
\hline 7 & For & Against & For & 0 & 2 & 0 & 1 \\
\hline 8 & For & Against & For & 1 & 0 & 1 & 1 \\
\hline 9 & For & Against & For & 0 & 0 & 0 & 0 \\
\hline \multirow[t]{3}{*}{$10 * *$} & For & Against & For & 1 & 2 & 1 & 3 \\
\hline & & & Total & 4 & 4 & 3 & 9 \\
\hline & & & $\mathrm{M}$ & 0.4 & 0.4 & 0.3 & 0.9 \\
\hline
\end{tabular}




\begin{tabular}{|c|c|c|c|c|c|c|c|}
\hline & 2nd paragraph & 3rd paragraph & $\begin{array}{c}\text { Conclusion } \\
\text { (includes writer's opinion) }\end{array}$ & Introduction & 2nd paragraph & 3rd paragraph & Conclusion \\
\hline 1 & For & Against & Against & 0 & 0 & 0 & 0 \\
\hline 2 & Against & For & For & 0 & 0 & 0 & 1 \\
\hline 3 & For & Against & Against & 0 & 1 & 0 & 0 \\
\hline $4 * *$ & Against & For & For & 1 & 1 & 1 & 2 \\
\hline $5 * *$ & Against & For & For & 1 & 1 & 2 & 1 \\
\hline 6 & For & Against & Against & 0 & 0 & 2 & 0 \\
\hline 7 & For & Against & Against & 0 & 0 & 0 & 2 \\
\hline 8 & For & Against & Against & 0 & 0 & 0 & 0 \\
\hline 9 & For & Against & Against & 0 & 0 & 0 & 1 \\
\hline \multirow[t]{2}{*}{$10^{* *}$} & Against & For & For & 1 & 1 & 1 & 1 \\
\hline & & & Total & 3 & 4 & 6 & 8 \\
\hline
\end{tabular}

Note. ${ }^{* *}$ These are target learners.

In response to the interview question, "Why did you write the word should in each paragraph?," three learners commented as follows.

Student No. 4:

I do not know exactly why I wrote the word "should" in these particular paragraphs. However, my understanding of the usage of "should" is when the writer would like to admit the facts and express his/her opinions strongly. Therefore, I used the word "should" in the paragraphs and conclusion. In the first entry, I knew some words could emphasize the writer's opinions; however, I was careless about where I used the word.

This response indicates that learners' reasons for choosing a word might be unclear. However, some learners demonstrated their understanding that modal verbs "are used in arguing to position the writer and reader" (Knapp \& Watkins, 2010, pp. 206-207), which indicates that these learners had begun to consider the reader-writer relationship by the end of the second semester.

Student No. 5:

In both paragraphs, the third and the conclusion, I wanted to show my strong opinion as an "opponent to the death penalty." (1) I wanted to emphasize my opinion in paragraph three so I used "should" twice. (2) The reason I used "should" in the second paragraph in support of the death penalty was because I tried to represent the opinions of a person from the supportive group and voice their emotions in the sentences as well, even though my personal opinion was against the topic. In the first entry, I did not use "should" at all, because I did not know how to incorporate the word correctly.

Student No. 5 understood the functional and rhetorical meaning of should in the context of a discussion text. Moreover, s/he explained the reason for using it in particular paragraphs. Since this learner understood the rhetorical function of should, it should have appeared frequently in both the third and fourth paragraphs. However, we found the word should in the second paragraph despite the fact that its content contained an opposing explanation. Student No. 5 explained the importance of being in the opposite group to express his or her voice in the second paragraph, which was again influenced by the rhetorical meaning of should.

Student No. 10:

I am unsure about the reason why I wrote "should" in each paragraph. However, my understanding of how to use the word "should" is to place emphasis on the writer's opinion. In the first entry, I did not pay attention to these aspects.

Finally, the above interview result shows the student's uncertainty regarding the use of the word "should" in each paragraph. This learner continued to explain her/his understanding of the functional meaning of the target word.

\subsection{Research Question 2}

To investigate how the learners conceptualized the discussion text in the first and second entries, their responses to the following open-ended question in the self-reflection task were analyzed: "What are the most important things to learn, in your opinion, when analyzing a peer's discussion essay?" The results are summarized in Table 7 and indicate that although the learners did not have much prior experience in this genre of writing, they had a basic idea of the structure and some rhetorical functions, such as the use of conjunctions $(n=8)$, topic sentences, 
and supporting evidence $(n=5)$. Then, in the second entry, learners' understanding of participation changed. They paid less attention to the function of topic sentences and supporting evidence $(\mathrm{n}=0)$ and more attention to other rhetorical functions, such as modalities $(n=6)$, which create interpersonal meaning in this writing genre. Additionally, their understanding of the discussion genre's function, which is to express the writer's opinion ( $\mathrm{n}=$ $4)$, and the relationship between the final paragraph and the writer's opinion $(n=3)$ increased. This implies that the learners' understanding of the discussion essay increased.

Table 7. Learners' understanding of discussion essays in the pre- and post-instruction writing tasks

\begin{tabular}{llccc}
\hline & Comments & Pre- & Post- & Total \\
\hline 1 & Use of conjunctions & 8 & 1 & 9 \\
2 & Contents of the introduction & 5 & 1 & 6 \\
3 & Modality: Its functions and structure (auxiliary verbs and adverbs) & 0 & 6 & 6 \\
4 & The authors' argument points & 1 & 4 & 5 \\
5 & Topic sentence and supporting evidence & 4 & 0 & 4 \\
6 & Structures & 2 & 2 & 4 \\
7 & Conclusion (expressing the author's opinion) & 1 & 3 & 4 \\
8 & Use of academic words & 3 & 0 & 3 \\
9 & Adjusting the nuance & 0 & 2 & 2 \\
10 & Lexicon & 1 & 1 & 2 \\
\hline
\end{tabular}

The pre- and post-instruction self-reflection written texts were analyzed using the Grounded Theory Approach (GTA). The total numbers of words and sentences in both the pre- and post-instruction self-reflection written texts are summarized in Table 8 .

Table 8. Learners' understanding of discussion essay writing in the pre- and post-instruction writing tasks

\begin{tabular}{lccccc}
\hline & Token & Types & Sentences & Paragraphs & N \\
\hline Pre & 1552 & 349 & 60 & 12 & 15 \\
Post & 1171 & 261 & 40 & 10 & 14 \\
\hline
\end{tabular}

The results of an in-depth analysis of the learners' genre awareness are shown in Figures 2 and 3, which show their basic understanding of the structure of discussion genre texts and which paragraphs should contain the argument for or against the topic. Figure 2 is a category relationship diagram of the results of GTA analysis of the data, which comprised pre-instruction self-reflection written texts. The top part of the diagram can be categorized as (1) Composition of genre, and the part below as (2) Linguistic characteristics.

Concerning (1) Composition of genre, there were many descriptions concerning awareness or understanding of the four paragraphs that are characteristically included in discussion essays. Moreover, the move analysis results related to the introduction (paragraph 1), are described. It was revealed that learners demonstrated an understanding of the consistency of the contents of the first paragraph (introduction), second paragraph, and later paragraphs. These descriptions concerning understanding of (1) Composition of genre were linked to descriptions of the "reader-writer relationship," suggesting that they understood what elements of the genre were required to write a discussion essay. This may provide an understanding of the consciousness of an EFL learner. The bottom part of Figure 2, the GTA category relationship diagram, summarizes the "linguistic characteristics" of a discussion essay, which related to three matters: impersonal pronouns, conjunctions, and TS and support evidence. Many descriptions were related to topic sentences and support evidence, which are given in one paragraph, showing that regarding the need for and functions of TS and support evidence, descriptions are related to the reader-writer relationship. 


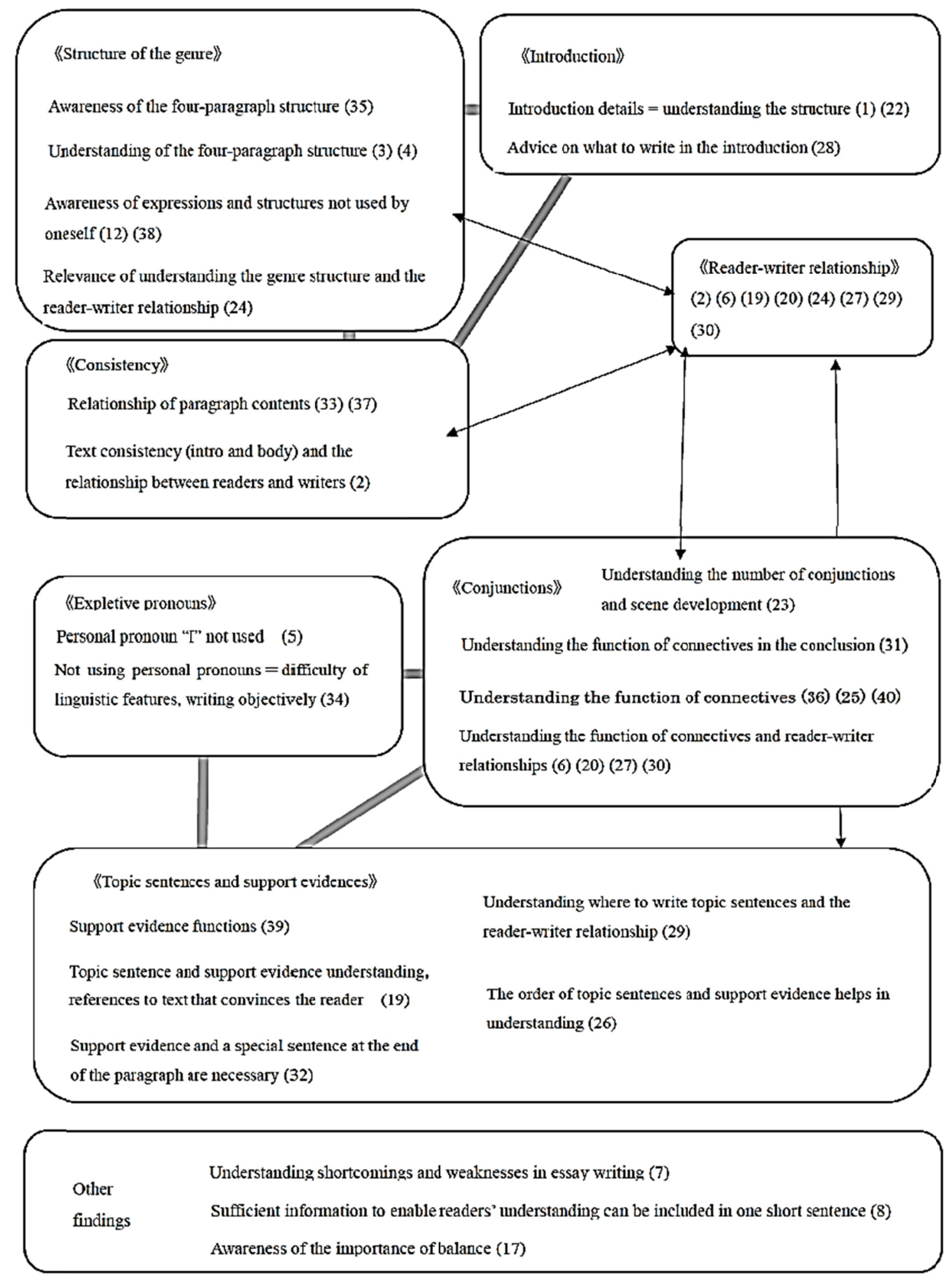

Figure 2. Result of GTA category map: self-reflection on the genre analysis of peer essays, first entry 
Figure 3 is a category relationship diagram of the results of GTA analysis of the post-instruction self-reflection written texts data. The top part of the diagram could be categorized as (1) Composition of genre, and the bottom part as (2) Linguistic characteristics. Concerning (1) Composition of genre, there were not only descriptions concerning awareness or understanding of the four characteristic paragraphs of a discussion essay, but also of strategies that theoretically strengthen the author's opinions. One example is: "I understood that in order to strengthen the opinions of the author in a case where I want to write the opinion of the opposed group (concerning the topic) in the final paragraph (Fourth paragraph; conclusion), that first writing the opinions of the group in favor of the topic in the second paragraph, and then writing the opinions of the group opposed to the topic in the second paragraph, would strengthen the assertions of the author (opinions of the opposed group) 31)." Furthermore, self-reflective texts that pointed out the error of not writing a peer essay using the discussion genre composition were observed. For example, "In this article, I think that even though I should have written concurring opinions, opposed opinions, and my own opinions in detail, in this composition, information about the present situation and the opinions of the author were insufficient (13)." A point of difference from the pre-instruction self-reflection written texts in the first term is that no descriptions were given in relation to the consistency of the introduction with the other paragraphs. Moreover, in the first term, no descriptions were given of the purpose of the discussion genre while one learned described it in his/her post self-reflection written text. An example is "This genre is a discussion, and the purpose of this genre is ultimately to advise the writer by introducing two perspectives on the problem point (27)." Next, descriptions concerning (2) linguistic characteristics included many descriptions of modalities using auxiliary verbs and adverbs. 


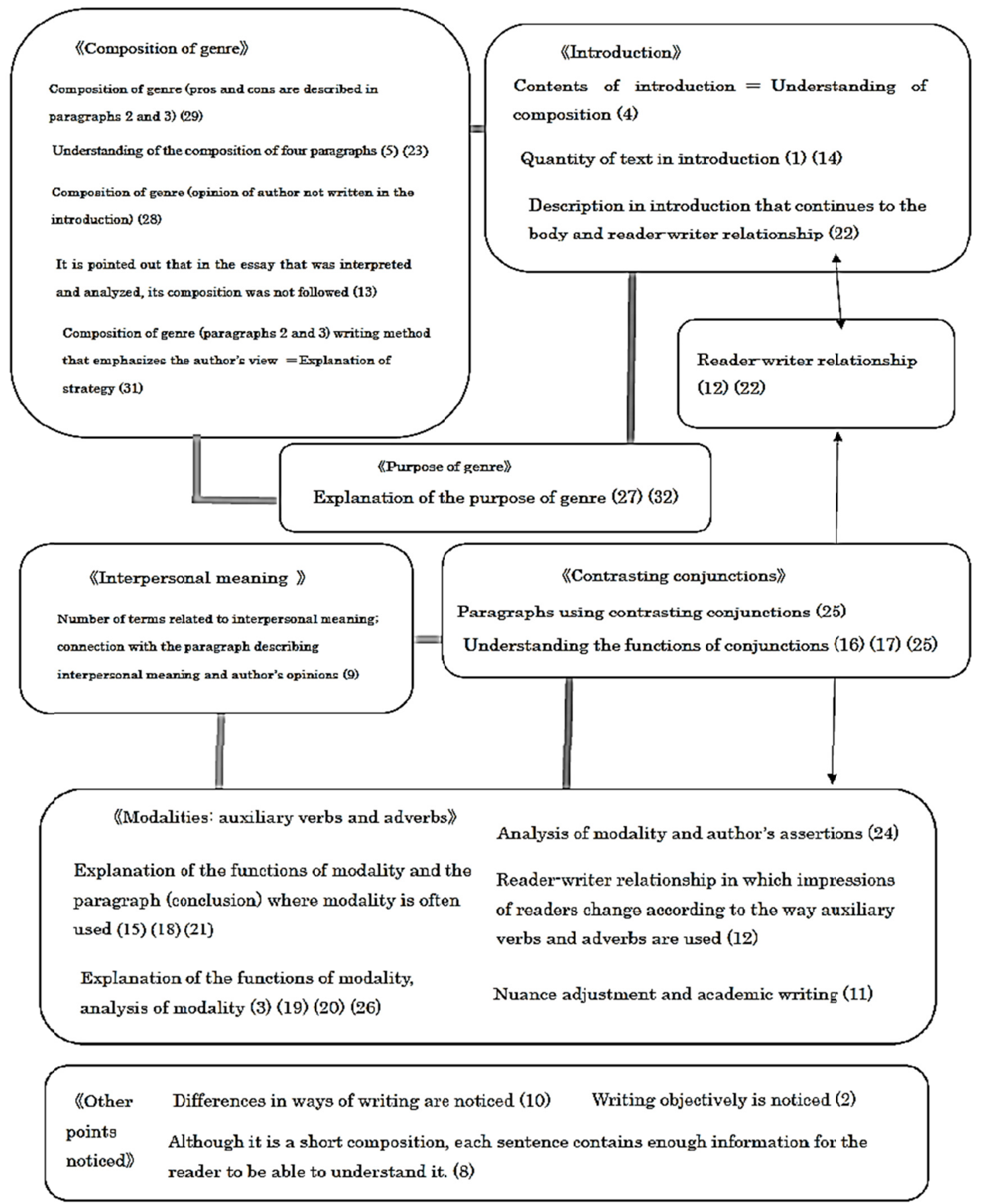

Figure 3. Result of GTA category map: self-reflection on the genre analysis of peer essays, second entry

\section{Discussion}

This study has examined the development of Japanese EFL undergraduate learners' genre awareness and lexicogrammatical choices in discussion essays during a two semester-long course. Learners' genre awareness was also explored using the concept of Lave and Wenger's CoP participation degrees: peripheral, active, and core members. The pedagogical effectiveness of the SFL genre-based approach to language learning in EFL CoPs was then examined in a Japanese context.

The results demonstrated that in the pre-instruction writing task, most learners tended to use the modal verbs can, should, and will, with more than half of learners using them without any understanding of their functions. The 
genre awareness data from the interviews and essay analyses showed that learners were familiar with the functional meaning of the verbal auxiliaries should, must, can, could, and will. For instance, these learners understood that the words should and must include the nuances of mandatory and obligational meanings, and they were taught that these meanings were almost the same as their corresponding Japanese versions-subeki. They were also taught the meanings of can and could, which shows why can was used to describe the present and could to describe the past instead of degrees of possibility (e.g., can $=$ there is a higher possibility that a thing will happen, could $=$ there is less certainty). Overall, the learners' lack of familiarity with genre conventions and their negligible understanding of the rhetorical meaning and functions of particular words was demonstrated in their first semester performances. Analysis of their post-instruction discussion essays in the second semester revealed that they had begun to apply the two main types of meaning in their writing, which influenced their lexicogrammatical choices. Their use of modal verbs in the pre-instruction writing texts shows the changes that occurred in their lexicogrammatical choices: They tended to use modal verbs in both the conclusion and supporting paragraphs. By the end of the second semester, many learners expressed their understanding of the target genre structure and modal verbs in their essays and tended to use fewer modal verbs in the first paragraph to maintain their subjective position.

An in-depth GTA analysis of the learners' meaning-making choices indicated the changes in their genre awareness. The results (Figure 2) showed that they gained awareness of the discussion genre structure as interpersonal or pragmatic. Regarding their understanding of discussion genre language features, they gained the ability to make appropriate mode choices (textual meaning) such as the use of contrast conjunctions. On the other hand, the post-instruction self-reflection written texts demonstrated that they were not only able to identify the genre structure but also its sociocultural purpose. Their understanding of the need to make appropriate tenor choices (interpersonal meaning) such as modalities also improved.

What, then, triggered changes in how the learners used lexicogrammatical features and in their genre awareness over this relatively short period of time? Adopting Feez's (1998) teaching-learning cycle, the author designed the class to enable learners to learn, in a scaffolded manner, the objectives of a specific genre and the language features used therein, and to be capable of outputting their knowledge. The author also reflected on the characteristics of cooperative learning in the classroom. The premises were that the CoP concept includes elements of cooperative learning, that cooperative learning requires planning and task sharing, and that there is a platform for or opportunity to construct inter-group communication. The teaching-learning cycle in the present study included elements of both cooperative and active learning. As a project-based form of learning, Sakamoto (2008) argued that cooperative learning allows learners not only to share a common understanding of learning goals and challenges but also to share values and outcomes with other learners, which in turn fosters a $\mathrm{CoP}$ and a culture of learning. Through the sharing of common goals and tools, cooperative learning has common ground with the CoP model.

Recently, there has been growing interest in the conditions under which peripheral members become experienced members of the classroom CoP. Ohba (2015) argued that, in English language learning classes centered on the mastery of communication skills, interaction enables the input, output, and feedback necessary to learn a second language. He also demonstrated how effective pair and group work can be and argued that lively interaction will not necessarily be achieved merely by seating learners close to the teacher and issuing instructions on how to complete tasks. The key to effective learning in EFL writing lies in two components of Feez's teaching-learning cycle used in this research; namely, joint and independent construction of texts.

According to Nemoto (2012), to master a writing genre requires mastering the skills necessary to use language appropriately in a specific social context and its peripheral contexts. If this is the case, the learning that occurred in this study involved mastery of the skills necessary to use language appropriately in a CoP university EFL classroom context. The data obtained revealed that many of the core and active members did not master the grammar, vocabulary, and target words as well as they mastered knowledge concerning the text genre. They also mastered the ability to use such knowledge appropriately, which enabled them to perform the writing tasks. While the peripheral members made copious self-reflective notes concerning their knowledge of the appropriate grammar, vocabulary, and target words, they tended to make relatively few notes on the composition of the genre in general. The expansion in learners' knowledge of the genre occurred through cooperative learning rather than via the unilateral transmission of knowledge from teacher to learners.

\section{Acknowledgments}

This work was supported by the Japan Society for the Promotion of Science Grant-in-Aid for Young Scientists (B) Grant Number JP16K16891. 


\section{References}

Agterberg, M., van den Hooff, B., \& Huysman, M. (2011). Cracking the core: How core members of electronic networks of practice contribute to organizational learning. Proceedings of the Organization Learning, Knowledge and Capabilities Conference 2011 (pp. 1-19). Hull, UK: Hull University Business School. Retrieved from http://www2.warwick.ac.uk/fac/soc/wbs/conf/olkc/archive/olkc6/papers/id_171.pdf

Aguirre-Muñoz, Z., Park, J. E., Amabisca, A., \& Boscardin, C. K. (2009). Developing teacher capacity for serving ELLs' writing instructional needs: A case for systemic functional linguistics. Bilingual Research Journal, 31(1-2), 295-322. https://doi.org/10.1080/15235880802640755

Al Badi, I. A. H. (2015). Academic writing difficulties of ESL learners. Proceedings of the 2015 WEI International Academic Conference (pp. 65-78). Barcelona, Spain. Retrieved from https://www.westeastinstitute.com/wp-content/uploads/2015/02/Ibtisam-Ali-Hassan-Al-Badi-full-Paper.pdf

Browne, C. M., \& Wada, M. (1998). Current issues in high school English teaching in Japan: An exploratory survey. Language Culture and Curriculum, 11(1), 97-112. https://doi.org/10.1080/07908319808666543

Cambridge, D., Kaplan, S., \& Suter, V. (2005). Community of practice design guide: A step-by-step guide for designing \& cultivating communities of practice in higher education. Retrieved from http://net.educause.edu/ir/library/pdf/nli0531.pdf

Chen, Y. S., \& Su, S. W. (2012). A genre-based approach to teaching EFL summary writing. ELT Journal, 66(2), 184-192. https://doi.org/10.1093/elt/ccr061

Cox, A. (2005). What are communities of practice? A comparative review of four seminal works. Journal of Information Science, 31(6), 527-540. https://doi.org/10.1177/0165551505057016

Derewianka, B. (2003). Trends and issues in genre-based approaches. RELC Journal, 34(2), 133-154. https://doi.org/10.1177/003368820303400202

Eggins, S. (2004). Introduction to systemic functional linguistics. London, England: A\&C Black.

Feez, S. (1998). Text-based syllabus design. Sydney, Australia: Macquarie University/AMES.

Flick, U. (2014). An introduction to qualitative research deitoin 5. Sage.

Funatsu, M., \& Hougetsu, M. (1995). Symbolic interactionism. Tokyo, Japan: Kouseisha Kouseikaku.

Guanxia, L. (2006). A course-book on functional grammar. Beijing, China: Foreign Languages Press.

Halliday, M. A. (1994). Functional grammar. London, England: Edward Arnold.

Halliday, M. A. K., \& Matthiessen, C. M. (2004). Halliday's introduction to functional grammar. London, England: Routledge.

Halliday, M., \& Matthiessen, C. M. (2014). An introduction to functional grammar. London, England: Routledge.

Horowitz, R., \& Samuels, S. J. (1987). Comprehending oral and written language. San Diego, CA: Academic Press.

JACET Kansai Chapter Writing Teaching Group (Ed.). (1995). Daigaku ni okeru eisakubun shido no arikata: Eisakubun jittai chosa no hokoku [English writing instruction at the university level in Japan: A survey of English writing instruction]. Kyoto, Japan: Authors. Retrieved from http://ci.nii.ac.jp/els/110008682322.pdf?id=ART0009761607\&type=pdf\&lang=en\&host=cinii\&order_no= \&ppv_type $=0 \&$ lang_sw $=\&$ no $=1490490378 \& \mathrm{cp}=$

Kinoshita, Y. (2003). The practice of grounded theory approach: Invitation to qualitative research [in Japanese]. Kobundo: Tokyo.

Knapp, P., \& Watkins, M. (2010). Genre, text, grammar: Technologies for teaching and assessing writing. Sydney, Australia: UNSW Press.

Lave, J., \& Wenger, E. (1991). Situated learning: Legitimate peripheral participation. Cambridge, England: Cambridge University Press. https://doi.org/10.1017/CBO9780511815355

Li, L. C., Grimshaw, J. M., Nielsen, C., Judd, M., Coyte, P. C., \& Graham, I. D. (2009). Evolution of Wenger's concept of community of practice. Implementation Science, 4(1), 1-8. https://doi.org/10.1186/1748-5908-4-11

Mao, Z., Li, N., \& Xue, J. (2014). Corpus functional stylistic analysis of modal verbs in Major Barbara and its 
Chinese versions. Theory and Practice in Language Studies, 4(1), 70-78. https://doi.org/10.4304/tpls.4.1.70-78

Martin, J. R. (1984). Language, register and genre. In F. Christie (Ed.), Language studies: Children writing reader (pp. 21-30). Geelong, Victoria: Deakin University Press. https://doi.org/10.1016/j.linged.2009.01.003

Martin, J. R. (2001). Cohesion and texture. In D. Schiffrin, D. Tannen, \& H. Hamilton (Eds.), The handbook of discourse analysis (pp. 35-53). Oxford, England: Blackwell.

Martin, J. R. (2009). Genre and language learning: A social semiotic perspective. Linguistics and Education, 20(1), 10-21. https://doi.org/10.1016/j.linged.2009.01.003

Martin, J. R., \& Rose, D. (2008). Genre relations: Mapping culture. London, England: Equinox.

Martin, J. R., \& Rose, D. (2012). Learning to write/learning to learn: Genre, knowledge and pedagogy in the Sydney school. London, England: Equinox.

McCarthy, M. (1998). Spoken language and applied linguistics. Cambridge, UK: Cambridge University Press.

Mohammad, T., \& Hazarika, Z. (2016). Difficulties of learning EFL in KSA: Writing skills in context. International Journal of English Linguistics, 6(3), 105-117. https://doi.org/10.5539/ijel.v6n3p105

Nemoto, H. (2012). The sociocultural approaches to second language acquisition research. Studies of Language and Culture, 16, 19-38. http://hdl.handle.net/2297/30517

Nishijo, M. (2017). Applying interpersonal meta-functional analysis into teaching English for football coaching [in Japanese]. Ritsumeikan University Language and Cultural Studies, 28(4), 245-268. Retrieved from http://www.ritsumei.ac.jp/acd/re/k-rsc/lcs/kiyou/pdf_28-4/lcs_28_4_nishijo.pdf

O'Donnell, M. (2011). Introduction to systemic functional linguistics for discourse analysis. Language, Function and Cognition, 2011-12. Retrieved from http://web.uam.es/departamentos/filoyletras/filoinglesa/Courses/LFC11/LFC-2011-Week1.pdf

Ohba, H. (2015). Implementing cooperative learning in the peer feedback process of EFL writing [in Japanese]. Proceedings of the Japan Society of English Language Education Kumamoto Chapter 2015 (pp. 226-227). Kumamoto, Japan: Kumamoto Gakuen University.

Preece, J. (2004). Etiquette, empathy and trust in communities of practice: Stepping-stones to social capital. Journal of Universal Computer Science, 10(3), 294-302. https://doi.org/10.3217/jucs-010-03-0294

Rose, D. (2011). Genre in the Sydney school. In J. Gee, \& M. Handford (Eds.), The Routledge handbook of discourse analysis (pp. 209-225). London, England: Routledge.

Rothery, J. (1996). Making changes: Developing an educational linguistics. In R. Hasan, \& G. Williams (Eds.), Literacy in society (pp. 86-123). London, England: Longman.

Saiki-Craighill, S. (2006). Words map grounded theory approach: to produce the theory [in Japanese]. Shinyoshya: Tokyo.

Saiki-Craighill, S. (2014). Overview of Grounded Theory Approach. Keio SFC journal, 14(1), 30-43. Retrieved from http://gakkai.sfc.keio.ac.jp/journal_pdf/SFCJ14-1-02.pdf

Sakamoto, J. (2008). What is "collaborative-learning"? Hosei University Career Design Conference Bulletin, 5 , 49-57, 2008-02 [in Japanese] NII Article ID (NAID)120003644687. Retrieved from http://hdl.handle.net/10114/6703

Sasaki, M., \& Hirose, K. (1996). Explanatory variables for EFL students' expository writing. Language learning, 46(1), 137-168. https://doi.org/10.1111/j.1467-1770.1996.tb00643.x

Sugihara, M. (2006). For pedagogical examination of "learning community" in university [in Japanese]. Kyoto University Research in Higher Education, 12, 163-170.

Tanaka, Y. (2008). Experts and novice. In T. Hidetsugu (Ed.), Gakushyushinrigaku no saisentan: Manabi no shikumi o kagakusuru [in Japanese], (pp. 122-133). Tokyo, Japan: Airi. Retrieved from http://kuir.jm.kansai-u.ac.jp/dspace/bitstream/10112/4538/1/KU-1100-20080500-1.pdf

Terashita, T. (2011). Qualitative research methodology [in Japanese]. Japanese Journal of Radiological Technology, 67, 413-417. http://doi.org/10.6009/jjrt.67.413

Troyan, F. J. (2013). Investigating a genre-based approach to writing in an elementary Spanish program 
(Doctoral dissertation, University of Pittsburgh, Pittsburg).

Vygotsky, L. S. (1987). Thinking and speech. In R.W. Rieber, \& A. S. Carton (Eds.), The collected works of L.S. Vygotsky, Volume 1: Problems of general psychology (pp. 39-285). New York, NY: Plenum Press.

Wenger, E. (1998). Communities of practice: Learning, meaning, and identity. Cambridge, UK: Cambridge University Press.

Wenger, E., McDermott, R., \& Snyder, W. (2002). Cultivating communities of practice: A guide to managing knowledge. Boston, MA: Harvard Business School Press. https://doi.org/10.1017/CBO9780511803932

Wu, Y., \& Dong, H. (2009). Applying SF-based genre approaches to English writing class. International Education Studies, 2(3), 77-81. https://doi.org/10.5539/ies.v2n3p77

Yang, D. F., \& Goodyear, P. (2004). Pattern languages and genres for writing computer science discourse. In R. Atkinson, C. McBeath, D. Jonas-Dwyer, \& R. Phillips (Eds.), Beyond the comfort zone: Proceedings of the 21st ASCILITE Conference (pp. 339-347). Perth, Australia: ASCILITE.

Yang, Y. F. (2010). Developing a reciprocal teaching/learning system for college remedial reading instruction. Computers \& Education, 55(3), 1193-1201. https://doi.org/10.1016/j.compedu.2010.05.016

Yasuda, S. (2011). Genre-based tasks in foreign language writing: Developing writers' genre awareness, linguistic knowledge, and writing competence. Journal of Second Language Writing, 20(2), 111-133. https://doi.org/10.1016/j.jslw.2011.03.001

Yasuda, S. (2015). Exploring changes in FL writers' meaning-making choices in summary writing: A systemic functional approach. Journal of Second Language Writing, 27, 105-121. https://doi.org/10.1016/j.jslw.2014.09.008

Zhuanglin, H. (2005). Introduction to systemic functional linguistics. Beijing, China: Peking University Publishing House.

\section{Copyrights}

Copyright for this article is retained by the author(s), with first publication rights granted to the journal.

This is an open-access article distributed under the terms and conditions of the Creative Commons Attribution license (http://creativecommons.org/licenses/by/4.0/). 